\title{
Arbuscular mycorrhizal inoculation enhances plant growth and changes root system morphology in micropropagated Annona cherimola Mill
}

\author{
C Azcón-Aguilar 1*, IG Padilla 2, CL Encina 2, R Azcón 1, JM Barea ${ }^{1}$ \\ 1 Departamento de Microbiología del Suelo y Sistemas Simbióticos, Estación Experimental del Zaidín, CSIC, Granada; \\ 2 Estación Experimental La Mayora, CSIC, Málaga, Spain
}

(Received 30 July 1996; accepted 23 September 1996)

\begin{abstract}
Summary - The effect of arbuscular mycorrhizal formation on plant development and root system morphogenesis in micropropagated Annona cherimola plants was investigated. A juvenile rootstock was used and already rooted in vitro plantlets were inoculated with arbuscular mycorrhizal propagules at the beginning of their acclimatization phase. Mycorrhization improved plant development (root, steam and leaves), but decreased the specific root length. Arbuscular mycorrhizal formation did not change the degree of branching nor the lateral root frequency for the adventitious roots, but significantly increased the intensity of branching of the first-order laterals. These results corroborate the role of arbuscular mycorrhizal symbiosis inducing beneficial changes in root system morphology and in the general developmental pattern in micropropagated plants.
\end{abstract}

Annona cherimola / arbuscular mycorrhiza / micropropagation / root system morphology

Résumé - L'inoculation de mycorhizes arbusculaires augmente la croissance de la plante et change la morphologie du système racinaire d'Annona cherimola Mill micropropagés. L'effet de la formation de mycorhizes arbusculaires sur le développement de la plante et la morphogenèse du système racinaire d'Annona cherimola a été étudié. Un porte-greffe juvénile a été utilisé et des plantes déjà enracinées in vitro ont été inoculées avec des propagules de mycorhizes arbusculaires au début de la période d'acclimatation. La mycorhization améliore le développement de la plante (racines, tiges, feuilles) mais diminue la longueur spécifique des racines. La formation de mycorhizes arbusculaires ne change pas pour les racines adventives, ni le degré d'embranchement, ni la fréquence des racines latérales, mais augmente sensiblement l'intensité des branchements des racines de premier ordre. Ces résultats corroborent le rôle de la symbiose mycorhizienne dans l'induction de changements bénéfiques au niveau de la morphologie du système racinaire et en général du développement de plants micropropagés.

Annona cherimola / mycorhize arbusculaire / micropropagation / morphologie du système racinaire

\footnotetext{
${ }^{*}$ Correspondence and reprints
} 


\section{INTRODUCTION}

Annona cherimola Mill, cherimoya, a tropical fruit tree belonging to the Annonaceae family of the Magnoliales native to South America (Gausen et al, 1982), is a plantation crop well adapted to the subtropical conditions of southern Spain, where it is successfully cropped in the Granada and Málaga provinces (Morton, 1987). The rooting pattern of this fruit tree suggests its mycotrophic habit, a fact that was corroborated in previous studies in which Annona showed a strong dependence on arbuscular mycorrhizal (AM) formation for optimal growth and development (AzcónAguilar et al, 1994a, b).

The role of $\mathrm{AM}$ establishment benefiting the survival and development of most of the plants produced in vitro has been demonstrated (AzcónAguilar and Barea, 1996; Lovato et al, 1996). This is particularly important for highly mycotrophic plants, like A cherimola; thus AM inoculation appears as a critical factor for the development of the micropropagated Annona plants, at the weaning stages. Apart from the well known improvement in mineral nutrition resulting from AM formation, other effects on plant physiology and morphology can be induced as a consequence of $\mathrm{AM}$ formation. In this context, it has recently been recognized that $A M$ colonization affects a range of morphological parameters in developing root systems (Atkinson et al, 1994). This can be of particular interest for micropropagated plants (Azcón-Aguilar and Barea, 1996; Lovato et al, 1996) because of the poorly developed root system they produce in vitro which, at least in part, accounts for the high mortality rates on transfer to ex vitro stages. The most commonly described effect of AM inoculation on root development is an increase in root branching. However, other parameters, such as the length of lateral roots, specific root length, etc, have also been demonstrated to be affected by AM colonization (Schellenbaum et al, 1991; Hooker et al, 1992; Berta et al, 1993, 1995; Atkinson et al, 1994).

Accordingly, a series of experiments was designed with the aim of ascertaining the effects of AM fungi on root system morphology in already rooted in vitro plants of $A$ cherimola inoculated at the beginning of their acclimatization phase.

\section{MATERIALS AND METHODS}

Cultures of Annona cherimola Mill cv Fino de Jete were initiated from nodal segments of semi-hardwood Annona cuttings following the procedures described by Pliego-Alfaro and Murashige (1987). Shoots were incubated in a basic medium consisting of MS (Murashige and Skoog, 1962) salts, added with i-inositol (100 $\mathrm{mg} / \mathrm{L})$, thiamine $(100 \mathrm{mg} / \mathrm{L})$, pyridoxine $(50 \mathrm{mg} / \mathrm{L})$, nicotinic acid $(50 \mathrm{mg} / \mathrm{L})$, glycine $(200 \mathrm{mg} / \mathrm{L})$, benzilaminopurine $(0.15 \mathrm{mg} / \mathrm{L})$, sucrose $(30 \mathrm{~g} / \mathrm{L})$ and TC agar $(8 \mathrm{~g} / \mathrm{L})$. Shoot cuttings, $2.5-3.0 \mathrm{~cm}$ long, were removed from the proliferative clumps and prepared for rooting.

The rooting procedure was essentially that described by Azcón-Aguilar et al (1994a). in summary, the shoot cuttings were placed in test tubes $(25 \times 150$ $\mathrm{mm}$ ) containing the basic medium, added with $1 \mathrm{~g} / \mathrm{L}$ activated charcoal. They were incubated in light for 3 days, being then subcultured for root induction in a medium similar to the basic one but supplemented with indolebutyric acid $(100 \mathrm{mg} / \mathrm{L})$ and citric acid $(200 \mathrm{mg} / \mathrm{L})$, with the sucrose content reduced to $15 \mathrm{~g} / \mathrm{L}$. Cultures were then incubated for 7 days in darkness, and for a further 3 days in light. Finally, shoots were subcultured in a root initiation/elongation medium which differed from the basic one in that the amount of macro-elements was halved, the content of sucrose rose to $20 \mathrm{~g} / \mathrm{L}$ and the indolebutyric acid was not added. Cultures were maintained for approximately 2 weeks in light.

All media were adjusted to $\mathrm{pH} 5.7$ prior to autoclaving and the environmental conditions during the rooting phase were $26 \pm 1{ }^{\circ} \mathrm{C}$, and $16 \mathrm{~h}$ light exposure to 2000 lux illumination (Sylvania regular spectrum GroLux Lamps, Canada) during the light periods.

At the end of the root initiation/elongation phase, most plantlets had some roots of about $1 \mathrm{~cm}$ long. At this stage they were inoculated with $A M$ propagules and brought into acclimatization.

Previous studies (Azcón-Aguilar et al, 1994a) recommended AM inoculation immediately after the acclimatization phase; however, because the aim of this experiment was to study the effect of AM symbiosis on root system morphology, inoculation was practised at the beginning of the acclimatization period. Plantlets were individually transferred to open pots $(100 \mathrm{~mL})$ containing a mixture of sterile soil and sand $(1: 1, v / v)$ and placed in a misting tunnel $(100 \%$ relative humidity) for 4 weeks. They were then transferred to another tunnel without mist for another 2 weeks and, at the end of this period, plants were transplanted to bigger pots $(250 \mathrm{~mL})$ and then to normal greenhouse conditions $\left(25 / 19{ }^{\circ} \mathrm{C}\right.$ day/night temperatures, $16 / 8 \mathrm{~h}$ photoperiod, $75 / 90 \%$ relative humidity). Hoagland nutrient solution (Hoagland and Arnon, 1983) at 25\% strength was used to feed the plants at the rate needed to maintain a suitable soil water content. The AM inoculum consisted of thoroughly mixed rhizosphere sam- 
ples of stock cultures, containing spores, hyphae and mycorrhizal root fragments of the AM fungus Glomus intraradices. Twenty plantlets per treatment were grown.

Two different experiments were carried out. The first one was a short-term experiment (10 weeks long) designed to establish protocols and experimental conditions. At harvest plant height, the number of leaves, shoot and root weight and root length of adventitious and first-order laterals were recorded.

In the second experiment, and after 8 weeks of growth in the greenhouse, plants were transferred to pots $(1000 \mathrm{~mL})$ containing a peat:sterile soil:sand $(2: 1: 1, v / v)$ mixture. At harvest, after a 20 week growth period, similar growth parameters as for the first experiment were determined, but a more detailed study of the root system morphology was performed. For root morphology measurements, roots were separated into branching orders and the length of the roots in each order measured using video images with a Digital Image Analysis (version 1.10 A, Delta T Devices Ltd, Burwell, Cambridge, UK).

In the second experiment the following morphometric parameters were determined: number of adventitious roots, number of roots of each order, length of the roots present in each order, total root length, degree of branching of the root system, lateral root frequency and specific root length (Berta et al, 1995). The following formula was applied:

Degree of branching $=$ total root number $/$ total root length

Lateral root frequency $=$ number of roots of order $n$ / length of roots of order $n-1$

Specific root length $=$ total root length $/$ total root weight

Data were analyzed by the analysis of variance and Tukey's test.

\section{RESULTS AND DISCUSSION}

Mycorrhizal inoculation substantially increased shoot and root biomass and leaf area (figs 1 and 3 ), corroborating the strong dependence of $A$ cherimola on mycorrhiza for optimal growth (Azcón-Aguilar et al, 1994a, b).

Data from the first experiment showed that AM inoculation increased total root length and, particularly, that of first-order laterals (fig 1). A significant effect of AM inoculation on root development was shown by plotting root length data against those of shoot weight (fig 2). These data show different regression lines for $A M$ and nonAM plants, which suggests a specific effect of AM infection on the production of first-order lateral roots.

In the second experiment the AM response can be summarized as follows: in general, inoculation improved the growth of root, steam and leaves (fig 3), and increased the number and length of the roots (fig 4) but, in turn, AM formation induced a decrease in the specific root length (fig 4). It did not change the degree of branching of the root system nor the lateral root frequency for the adventitious roots, but significantly increased the intensity of branching of the first-order laterals (fig 4).

Modifications in the morphology of the root system induced by AM colonization merit some comments. Morphological, modelling and topological methods have been used to investigate effects of AM on root morphology and/or archi-
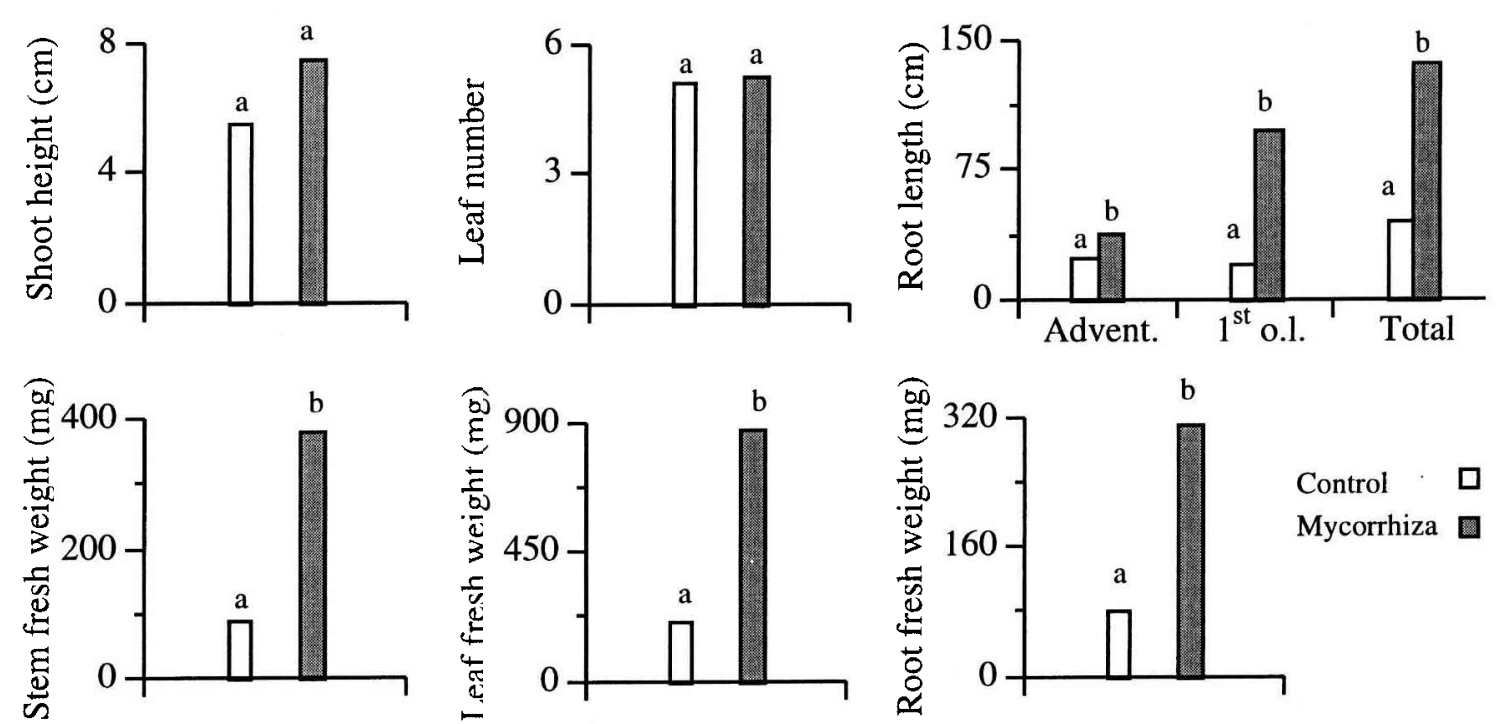

Fig 1. Effect of arbuscular mycorrhizal inoculation on several growth parameters (stem fresh weight, shoot height, leaf fresh weight, leaf number, root fresh weight, root length) of Annona cherimola plants micropropagated from a juvenile rootstock. Inoculation was done at the beginning of the acclimatization period and plantlets were 10 weeks old when harvested. For each parameter, mean values (20 replicates) sharing the same letter did not differ significantly $(P<0.05)$ according to Tukey's test. Advent.: adventitious roots; 1st o.l.: first-order laterals. 
tecture (Atkinson et al, 1994). In agreement with Fitter and Stickland (1991), Schellenbaum et al (1991), Berta et al (1993) and Atkinson et al (1994), the topological method allows architectural approaches which, in turn, make it possible to evaluate the costs and benefits of root architecture related to the root potential for soil resource exploitation. This type of assessment cannot be achieved by applying a morphological develop-

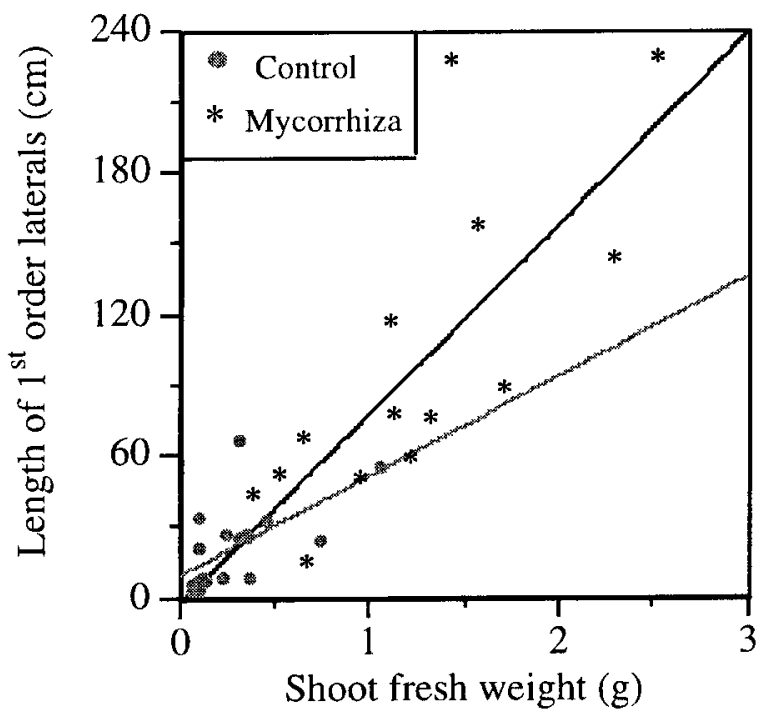

Fig 2. Correlation between length of first-order laterals and shoot weight for control and arbuscular mycorrhizal (Glomus intraradices) Annona cherimola plants. Inoculation was done at the beginning of the acclimatization period and plantlets were 10 weeks old when harvested. mental analysis. However, the latter is inherently dynamic and it is therefore most useful in describing changes which reflect developmental processes (Atkinson et al, 1994). Because this fits into the aims of the present study, a simple developmental method was used. Such an approach allowed us to detect changes in root morphology induced by the symbiotic interactions. One of the main effects derived from the mycorrhizal status was that the root number in any order lateral was increased as well as the length in all cases. This basically agrees with the findings by Schellenbaum et al (1991), Hooker et al (1992) and Berta et al (1995), in comparing $A M$ versus non-AM control plants. It is difficult to reach generalizable conclusions on the pattern of modifications induced by AM due to the complexity of the factors involved, such as AM fungal species, host plant, soil fertility and the prevailing environmental conditions (Schellenbaum et al, 1991; Atkinson et al, 1994).

The AM-induced decrease in the specific root length over time was similar to that found by Berta et al (1995), but the available data from the present study does not permit any further discussion of the reasons accounting for that pattern.

Overall, the results from the reported experiments corroborate the role of AM symbiosis inducing changes in root system morphology and, in general, in the developmental patterns in micropropagated plants. These changes lead to
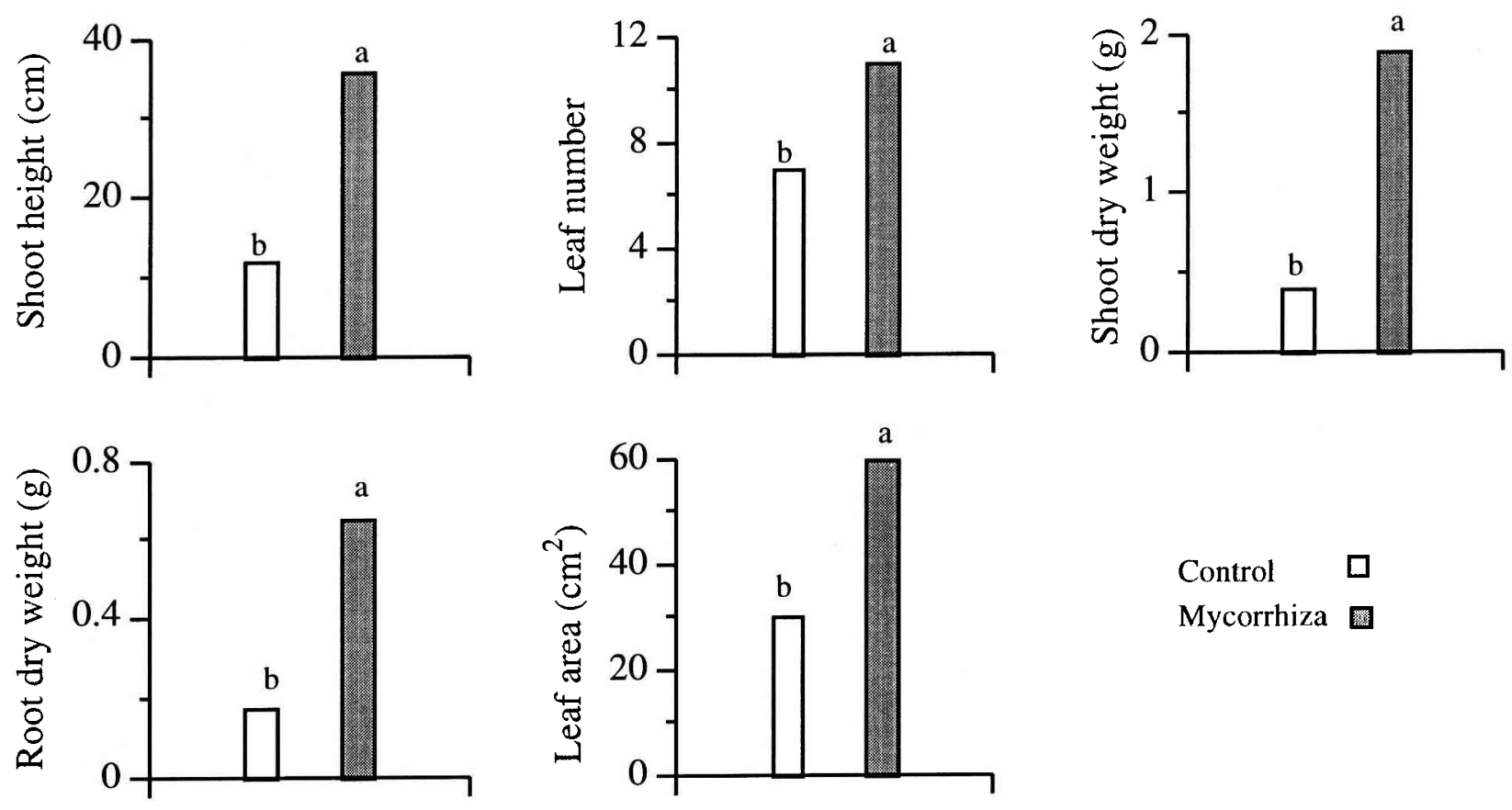

Control $\square$
Mycorrhiza

Fig 3. Effect of arbuscular mycorrhizal inoculation on several growth parameters (root dry weight, shoot height, leaf area, leaf number, shoot dry weight) of Annona cherimola plants micropropagated from a juvenile rootstock. Inoculation was done at the beginning of the acclimatization period and plantlets were 20 weeks old when harvested. For each parameter, mean values (20 replicates) sharing the same letter did not differ significantly $(P<0.05)$ according to Tukey's test. 
plantlets more efficient for nutrient acquisition and better equipped to cope with the stress situations characteristic of the micropropagation processes (Berta et al, 1995). They also support
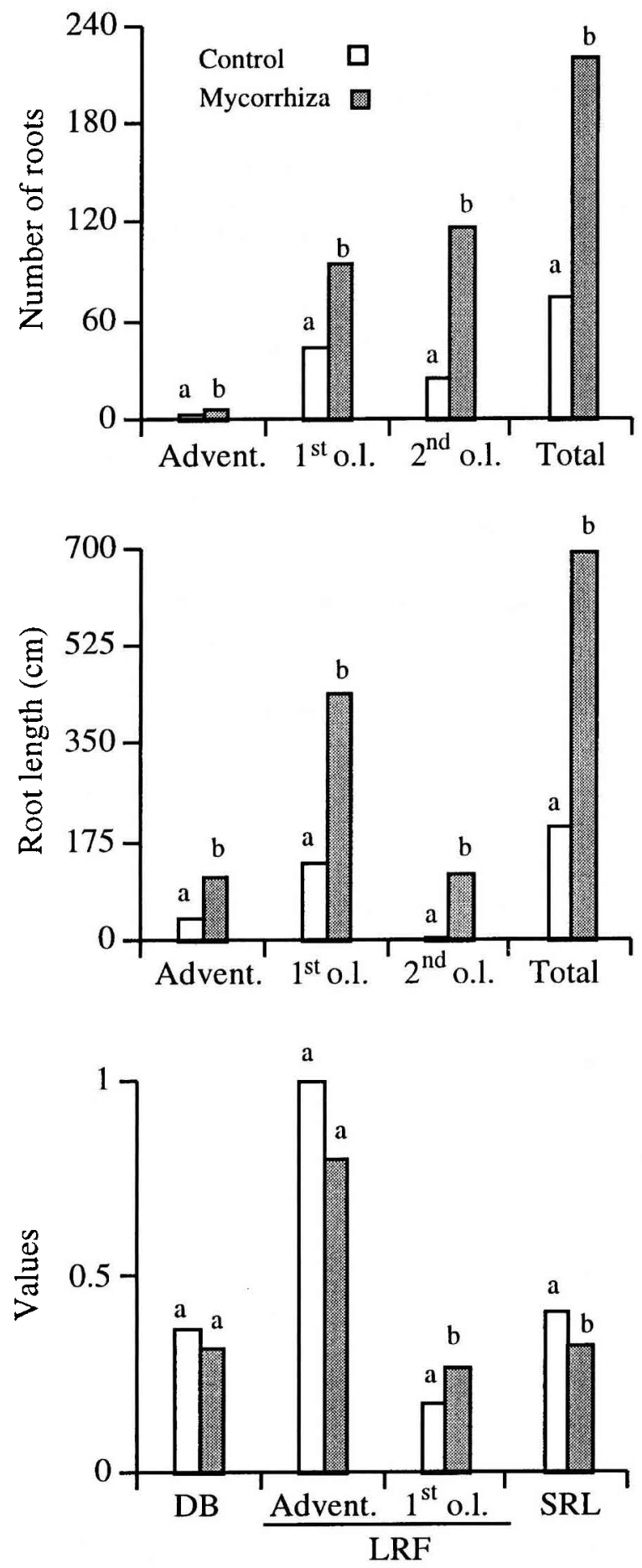

Fig 4. Effect of arbuscular mycorrhizal inoculation on root system morphology of Annona cherimola plants micropropagated from a juvenile rootstock. Inoculation was done at the beginning of the acclimatization period and plantlets were 20 weeks old when harvested. For each parameter, mean values (20 replicates) sharing the same letter did not differ significantly $(P<0.05)$ according to Tukey's test. Advent.: adventitious roots; 1st o.l.: first-order laterals; 2nd o.1.: second-order laterals; DB: degree of branching; LRF: lateral root frequency; SRL: specific root length. the cooperation of both biotechnological approaches (micropropagation and mycorrhization) towards a more sustainable horticultural production (Azcón-Aguilar and Barea, 1996; Lovato et al, 1996).

\section{ACKNOWLEDGMENTS}

This study was supported by CICyT-Spain (Project AGF95-0588-C02-02). This work is included in the framework of activities of COST 8.21. We thank the European Union for supporting such COST Action.

\section{REFERENCES}

Atkinson D, Berta G, Hooker JE (1994) Impact of mycorrhizal colonisation on root architecture, root longevity and the formation of growth regulators. In: Impact of Arbuscular Mycorrhizas on Sustainable Agriculture and Natural Ecosystems (S Gianinazzi, H Schüepp, eds), Birkhäuser Verlag, Basel, Switzerland, 89-97

Azcón-Aguilar C, Barea JM (1996) Applying mycorrhiza biotechnology to horticulture: significance and potentials. Sci Hort (in press)

Azcón-Aguilar C, Encina Cl, Azcón R, Barea JM (1994a) Effect of arbuscular mycorrhiza on the growth and development of micropropagated Annona cherimola plants. Agric Sci Finn 3, 281-288

Azcón-Aguilar C, Encina CL, Azcón R, Barea JM (1994b) Mycotrophy of Annona cherimola and the morphology of its mycorrhizae. Mycorrhiza 4, 161168

Berta G, Fusconi A, Trotta A (1993) VA mycorrhizal infection and the morphology and function of root systems. Environ Exp Bot 33, 159-173

Berta G, Trotta A, Fusconi A, Hooker JE, Munro M, Atkinson D, Giovannetti M, Morini S, Fortuna P, Tisserant B, Gianinazzi-Pearson V, Gianinazzi S (1995) Arbuscular mycorrhizal induced changes to plant growth and root system morphology in Prunus cerasifera. Tree Physiol 15, 281-293

Fitter AH, Stickland TR (1991) Architectural analysis of plant root systems. 2. Influence of nutrient supply on architecture in contrasting plant species. New Phytol 118, 383-389

Gausen H, Leroy JF, Ozenda P (1982) Précis de Botanique. In: Végétaux supérieurs (PP Grassé, ed), Masson, Paris, France, 221-230

Hoagland DR, Arnon DI (1983) The water culture method for growing plants without soil. Calif Agric Exp Sta Cir Berkeley, Berkeley, CA, USA, $347 \mathrm{p}$

Hooker JE, Munro M, Atkinson D (1992) Vesiculararbuscular mycorrhizal fungi induced alteration in poplar root system morphology. Plant Soil 145, 207 214 
Lovato PE, Gianinazzi-Pearson V, Trouvelot A, Gianinazzi $S$ (1996) The state of art of mycorrhizas and micropropagation. Adv Hort Sci 10, 46-52

Morton JF (1987) Fruits of Warm Climates (CF Dowling, ed), Editor Creative Resource System, FL, $505 p$

Murashige T, Skoog $F$ (1962) A revised medium for rapid growth and bioassays with tobacco tissue culture. Physiol Plant 15, 473-497
Pliego-Alfaro F, Murashige T (1987) Possible rejuvenation of adult avocado by graftage onto juvenile rootstocks in vitro. Hort Sci 22, 1321-1324

Schellenbaum L, Berta G, Ravolanirina F, Tisserant B, Gianinazzi S, Fitter AH (1991) Influence of endomycorrhizal infection on root morphology in a micropropagated woody plant species (Vitis vinifera $L$ ). Ann Bot 68, 135-141 